\title{
O CONTRATO DE COMUNICAÇÃO NA SALA DE AULA*
}

\author{
Patrick Charaudeau, \\ da Université de Paris XIII
}

\begin{abstract}
RESUMO: Não se pode reduzir o ato de comunicação a uma relação simétrica entre um emissor e um receptor; é necessário analisar as condições em que os sujeitos falantes reconhecem este direito recíproco de falar e construir sentido, para que o ato de comunicação se realize. Isso se dá em uma troca linguageira em que os parceiros reconhecem mutuamente o direito à palavra, ou seja, ambos entram em um contrato em que as partes buscam princípios, pertinência, influência e regulação comuns. Em uma situação de sala de aula, os parceiros contratam sua interação, de forma a construirem suas identidades, finalidades e papéis, para que os sentidos possam ser o resultado do ato de comunicação

Palavras-chave: Contrato de comunicação. Professor. Ensino. Sala de aula.
\end{abstract}

\section{A NOÇÃO DE CONTRATO DE COMUNICAÇÃO}

Falar sobre a comunicação humana significa inicialmente falar sobre o problema da identidade do sujeito falante, como ser comunicante, e, portanto, do seu direito a comunicar-se. Em outras palavras, para qualquer sujeito que queira falar, põe-se a questão de saber se existe algum fundamento para que possa fazer isso, caso contrário ele não existiria como sujeito falante.

Às vezes, há normas mais ou menos institucionalizadas que auxiliam nessa interrogação angustiante e parecem evitar que o sujeito falante se coloque essa questão. Assim, um conferencista, apresentado como tal,

\footnotetext{
* Tradução de Cristian Nicolas Gouraud (FL/UFG) e revisão de Luana Alves Luterman (UEG/PPLLUFG). Publicado, com o título Le contrat de communication dans la classe, em Inter-Actions, J.F. Halté, Université de Metz, 1993. 
durante um congresso, com seus títulos e funções, pode achar-se autorizado a falar. Igualmente, o animador de um debate, quando é reconhecido pelos outros parceiros, está autorizado a questionar; e um professor na sua sala de aula, desde que lhe seja reconhecido esse estatuto, é, ele também, autorizado a exercer certos papéis linguageiros (o que veremos mais adiante).

Essas normas, em geral, resultam do fenômeno de regulação das trocas comunicacionais do cotidiano, regulação que acaba instaurando práticas nas quais os membros de uma mesma comunidade cultural se reconhecem. O que, por exemplo, pode me autorizar a parar alguém na rua e lhe fazer uma pergunta? Por que, se pergunto a hora, ou a direção de uma estação, há fortes chances que ele me responda, e, portanto, aceite-me como locutor, ao passo que se peço dinheiro, ou a direção da estação de Montreal estando em Paris -, há grandes chances de que não responda, ou me mande plantar batatas, significando assim que não me reconhece como locutor? É que o "direito à palavra" para um locutor qualquer e seu reconhecimento pelo outro não dependem do único fato de que um tomaria a palavra e o outro reagiria. É preciso que o primeiro satisfaça, numa situação de troca, a várias condições (voltaremos ao assunto), e que o outro mostre, por um dado comportamento, que essas condições estão satisfeitas, reconhecendo satisfatoriamente esta palavra como autorizada, nesta situação específica, e fazendo existir seu interlocutor. Por isso, mesmo em situações de comunicação institucionalizadas, como as de conferência ou de sala de aula, nada está definitivamente resolvido. Todo conferencista, todo professor sabe que, além do vínculo institucional - cujo direito à palavra parece já ser conferido pela presença do público (ouvintes, alunos) -, é preciso ainda que the seja reconhecida uma identidade de sujeito competente.

O reconhecimento do "direito à palavra" e o reconhecimento da "identidade" do sujeito falante representam então as duas faces de uma mesma moeda, moeda de troca que circula entre os parceiros de um ato de comunicação.

Porém, falar a respeito de comunicação humana significa também falar do sentido que se constrói quando comunicamos, pois é necessário postular que a linguagem cria sentido. Entretanto, o sentido, numa concepção da comunicação que se fundamenta no "direito à palavra", não é unicamente "referencial", e a língua não serve somente - como se dizia na época estruturalista - para recortar o mundo.

Primeiramente direcionado aos parceiros do ato da linguagem, o sentido determina o modo de existência dos sujeitos falantes, e é fazendo isso que, do mesmo modo, constrói representações sobre o mundo. O sentido, embora seja uma ideia persistente, partilhada tanto pelo saber comum quanto 
por certas teorias cognitivistas, não é necessariamente fundado na verdade. Como lembra um filósofo da linguagem, o sentido se constrói na "teatralização generalizada da vida comunitária, o jogo cotidiano dos simulacros, consciente ou inconscientemente assumidos, a divisão dos papéis, a metaforização e a figuração de nossas palavras..."(PARRET, 198X). De fato, não é jamais a questão do outro ou de si, mas a de uma imagem de si ou do outro construída em função dos objetivos da comunicação.

O sentido é ao mesmo tempo nosso mito e nosso real. Constrói-se na confluência do dito e do não dito (do explícito e do implícito). Não é somente o dito, não é somente o não dito. Nasce da relação entre os dois. Quando dizemos "bom-dia!", quando realizamos uma conferência, quando passamos uma simples tarefa em sala de aula, há sempre, sob a aparente tranquilidade das palavras, uma torrente de significações implícitas.

É necessário, portanto, que sejam preenchidas certas condições para que os sujeitos falantes de uma comunidade social reconheçam este direito recíproco de falar e construir sentido, para que o ato de comunicação se realize.

Quais são, então, os princípios que se situam na base dessas condições de comunicação? Colocaremos quatro, indissociáveis uns dos outros:

a) Um princípio de interação que define o ato de comunicação como um fenômeno de troca entre dois parceiros, os quais se situam:

- numa relação não simétrica, visto que estão engajados, cada um por sua vez, em dois tipos de comportamentos: um que consiste em produziremitir palavra, o outro que consiste em receber-interpretar esta palavra;

- correlativamente, estão ligados pelo reconhecimento recíproco desses dois papéis de base, que só podem coexistir a partir do momento em que o outro, o interlocutor, engaja-se no processo de interpretação. De fato, não basta que este tenha o papel de um simples receptáculo mecanicista, como nas teorias behavioristas da comunicação. Estamos mostrando que, além do simples ato de recepção, ele se engajou num processo de interpretação, tornou-se um parceiro-interlocutor (ou destinatário-leitor) e consequentemente situou o emissor como seu parceiro-locutor.

Assim, instaura-se entre esses dois parceiros uma espécie de "olhar avaliador" recíproco que legitima o outro no seu papel de sujeito que comunica.

Podemos dizer que, segundo o princípio de interação, há o outro e há o eu, mas ao mesmo tempo "o outro constitui o eu". O ato de comunicação é o resultado de uma coconstrução.

Cada vez que, na situação de sala de aula, os alunos falam, fazem barulho ou parecem distraídos, o outro parceiro, o professor, não existe mais. 
Esses comportamentos testemunham que o aluno não se reconhece mais como parceiro do professor e, então, este último não está mais legitimado. Nessas condições, o princípio de interação não age mais. Não há mais possibilidade de coconstrução. O professor "fala para as paredes" (as quais, como se sabe, não podem ser consideradas como parceiras legítimas).

b) Um princípio de pertinência, que exige dois fatores:

- de um lado, que o interlocutor (ou o destinatário) possa supor a existência de uma intenção do locutor, um projeto de palavra, que dará ao ato de linguagem sua motivação, sua razão de ser;

- do outro lado, que locutor e interlocutor possuam em comum um mínimo dos dados que constituem este ato, do contrário não poderiam efetuar trocas linguageiras ("conversa de surdos"). Dizendo de outra maneira, que possam reconhecer a existência de certos saberes sobre o mundo, valores que são atribuídos a estes saberes, e normas que regulam os comportamentos sociais por meio de rituais linguageiros. Este conjunto representa o que na literatura sobre as análises conversacionais é denominado de "saberes compartilhados". Sem saberes compartilhados não há possibilidade de estabelecer uma intercompreensão e, portanto, nenhuma pertinência do ato de comunicação.

Um dos grandes problemas da situação de sala de aula reside nesta percepção dos saberes compartilhados. Certos saberes supostamente estão compartilhados em razão da comunidade de cultura, da classe social, da idade etc. (podemos, porém, fazer sempre tal suposição?); outros são construídos em função de saberes previamente adquiridos (contudo, quais são eles, e eles são os mesmos para todos os alunos?).

c) Um princípio de influência que considera que o que motiva a intenção do sujeito falante se inscreve numa finalidade acional (ou psicológica), e o obriga a se perguntar: "como devo falar para agir sobre o outro?". Responder a esta pergunta o levará a estabelecer estratégias de palavra.

Essas estratégias dependerão das postulações que cada sujeito que comunica fará sobre seu parceiro. A priori, pode perceber esse parceiro (tratase somente de imagens) como favorável, desfavorável ou indiferente a seu projeto de influência e, segundo essas postulações, poderá escolher como atingi-lo, utilizando estratégias de sedução, de convicção etc.

Segundo esse princípio, todo ato de comunicação é uma luta para o controle dos objetivos da comunicação.

Considerando esse ponto de vista, a escola, em algumas de suas representações, mantém um mal-entendido. Ela pressupõe, como se fosse 
óbvio, que a criança possui o desejo de aprender. Tal fato seria definitivamente favorável ao projeto de influência da sociedade por meio do saber do professor. Essas representações (presentes entre outros lugares nas Instruções oficiais - ver adiante) negam ao aluno um "não querer aprender", e a relação professor-aluno está assim concebida em termos de transmissão de saber e não de luta para o controle de objetivos diversos que exigem da parte dos parceiros o desenvolvimento de estratégias diversas.

d) Um princípio de regulação que determina, ao mesmo tempo, as condições para que os parceiros da comunicação entrem em contato e se reconheçam como parceiros legitimados, bem como determina as condições para que a troca comunicativa ocorra e se estabeleça, já que o princípio de influência instaura entre os parceiros uma relação de luta discursiva que provoca, cada vez que um dos dois cede terreno, a perda de parte de sua identidade, que pode até desaparecer completamente. Esse princípio de regulação permite ao sujeito comunicante estabelecer certas estratégias de base cuja finalidade consiste em assegurar a continuidade ou a ruptura da troca:

- aceitação/rejeição da palavra do outro e do estatuto do outro como ser comunicante (isto é, de seu "direito à palavra");

- valorização/desvalorização do parceiro, oferecendo-lhe o direito da palavra, o que pode levar a construir um tipo de "teoria das faces", conforme sugestão de Goffman (1974);

- reivindicação/confissão, da parte do sujeito falante, de sua identidade, que pode ser trazida a uma identidade coletiva de nós, para se diferenciar dos outros grupos, ou a uma identidade individual de $\boldsymbol{e u}$, para se diferenciar de todos os outros.

Na situação de sala de aula, é frequentemente pressuposto que existem dois tipos de parceiros: de um lado, o professor, do outro, os alunos considerados como uma entidade coletiva homogênea. No entanto, todo professor é um eu múltiplo, pois produz diversos tipos de discurso que se direcionam a parceiros diferentes (os alunos, a instituição, a sociedade etc.), e os alunos são ora eu face ao professor ou a outros alunos, ora nós face ao professor ou a outros grupos de alunos. É a partir deste conjunto de identidades diversas e de olhares cruzados que se regulam as trocas.

Esses quatro princípios - como já dissemos, indissociáveis uns dos outros - constroem o que eu denomino de "contrato de comunicação"."

Tal contrato determina uma parte da identidade dos parceiros, para que estes sejam legitimados na situação de troca na qual eles se situam, 
uma parte de suas finalidades, para satisfazer ao princípio de influência e de pertinência, e os papéis linguageiros que Ihes são atribuídos por conta do princípio de regulação.

O "contrato de comunicação" une os parceiros num tipo de aliança objetiva que lhes permite coconstruir sentido se autolegitimando. Se não há possibilidade de reconhecer tal contrato, o ato de comunicação não estabelece pertinência e os parceiros não possuem direito à palavra.

Numa situação de sala de aula, como em qualquer outra situação de comunicação, os parceiros supostamente compartilham o mesmo contrato, assim como certos valores e saberes que se estendem, como veremos a seguir.

Evidentemente, a execução discursiva de um ato de comunicação é muito mais rica e complexa do que essas estratégias de base na medida em que esses comportamentos podem ser jogados, podem se esconder uns dos outros, e deixar a intencionalidade do sujeito somente nas entranhas do implícito.

Verificamos, portanto, que não se pode mais reduzir o ato de comunicação a esta relação simétrica entre um emissor e um receptor como certas teorias da comunicação descreveram. A comunicação é, em cada ocorrência, todo o ser individual e social que está empenhado numa aposta:"como adquirir o reconhecimento do direito à palavra, e como atingir o outro-eu-próprio?".

\section{O CONTRATO DE COMUNICAÇÃO NA SALA DE AULA}

Primeiramente uma observação: não se pode confundir "contrato didático" e "contrato de sala de aula". O primeiro corresponde a toda situação que se define através de uma finalidade de transmissão de saber. Existem, contudo, diferentes tipos de contrato didático, segundo a especificidade da situação e a maneira como estão implicados os diferentes parceiros. Por exemplo, não será igual caso se trate de um "manual pedagógico", de uma "conferência", ou de uma "obra de vulgarização científica".

Quais são, então, os objetivos da comunicação desta situação de sala de aula e, particularmente, quais são os termos do contrato que sobredeterminam seus parceiros, do ponto de vista da identidade destes, das finalidades que lhes são próprias e dos papéis que lhes são atribuídos?

A conscientização dessas relações contratuais é uma das condições de base para que os participantes meçam qual é a margem de manobra que Ihes permitirá tanto manter seu direito à palavra quanto exercer sua influência sobre o outro.

Entretanto, antes de propor esta descrição, precisamos saber como proceder para definir tal contrato, investigando, de um lado, as trocas entre 
os parceiros para assinalar as constantes especíicas dessas relações de troca; do outro lado, analisando os discursos de representação que são produzidos numa comunidade cultural a respeito dessa situação, cujas instruções oficiais, declarações dos responsáveis políticos, textos legislativos e escritos sobre a escola constituem os suportes textuais privilegiados. São as convergências entre esses dois tipos de estudo que permitem pôr em evidência as características do contrato que apresentamos a seguir.

As "identidades" dos parceiros:

- O professor: não importa a maneira de nomeá-lo (professor, animador), o professor tem, a respeito da organização do mundo do trabalho, um estatuto socioprofissional (público ou privado) que o coloca em relação de dependência face à instituição (pública ou particular) que o emprega. Ele é, então, de certa forma, um representante da instituição escolar.

Além disso, supostamente possui uma competência de saber e de savoir-faire em relação à finalidade do contrato (domina um saber a transmitir/ sabe como o transmitir).

- O aluno: socialmente considerado como não adulto e não ativo, possui no sistema escolar um estatuto de assistido (é para ele que este sistema existe), mesmo porque o que justifica esse sistema é que o aluno se situa, do ponto de vista da competência, em um estado de não saber.

Em contrapartida, Ihe são atribuídas uma qualificação e uma competência. A qualificação é que está na obrigação social do aprender, pois isto é bom para ele. Às vezes esta obrigação é chamada "desejo de aprender" ou "desejo de saber". Correlativamente, supõe-se que tem uma dupla competência: de aprendizagem e de compreensão. De aprendizagem, na medida em que se supõe que ele está apto a adquirir saber; de compreensão, na medida em que podemos supor que ele possui a capacidade de entender o que vai ser ensinado (sem esta dupla competência, o edifício escolar não se justifica).

As "finalidades" de cada um dos parceiros:

Para o professor, uma tripla finalidade:

a) ensinar (propriamente falando), atividade que consiste em transmitir um saber (este concebido como um objeto de conhecimento e um savoir-faire relativo a uma disciplina), em uma relação triangular: professordisciplina de referência-aluno, para que o aprendiz passe de um estado de não saber a um estado de saber. O professor se inscreve nesta finalidade como mediador entre o saber de referência e o aluno, representando assim 
o papel de guia. O saber a ser transmitido é concebido como um objeto preexistente representando uma "verdade" (seja qual for a sua definição), boa para o homem (do contrário não seria ensinada). Quanto ao aluno, inscrevese nesta finalidade trabalhando, isto é, respondendo às instruções emitidas pelo professor (o contrato não teria êxito caso não se pudesse supor que o aluno trabalha - ver a seguir e mais adiante);

b) avaliar, atividade que consiste em verificar os resultados por meio primeiramente do grau de conformidade do "saber dizer" do aluno ao "saber dizer" apresentado como modelo (todo ensinamento de um saber é o ensinamento de um "saber dizer"); de outro lado, a progressão observada no processo de passagem do não saber ao saber do aluno. A organização e a programação do trabalho (em particular os programas escolares) estão concebidas de acordo com a ideia que se tem destas duas noções de conformidade e de progressão. Esta avaliação é feita por meio de notas e/ou de apreciações;

c) captar, atividade que consiste em enfrentar os obstáculos suscetíveis de surgir durante o processo de ensino/aprendizagem e que proviriam ou de um "não querer" do aluno (recusa, esquecimento, desatenção, tédio etc. - pelo menos é assim que estão classificadas essas atitudes nos discursos de representação), ou de um "não poder" deste (inaptidões intelectuais ou psicológicas, julgadas como tais pelos outros diferentes parceiros do sistema educativo).

Esta atividade de captação, veremos, não é necessariamente reconhecida por todos os parceiros do ensino (ver adiante: Comentários sobre o contrato), mas é uma realidade deste contrato a ponto de, como mostram as diferentes descrições das trocas de palavras na sala de aula, ocupar, em tempo linguageiro, a maior parte dos atos de fala do professor.

Para o aluno, uma dupla finalidade:

a) aprender (propriamente falando), atividade que consiste em adquirir saber, isto é, como já dissemos, reproduzir, por meio de uma maneira certa de dizer, um modelo que possui lugar de referência, de saber;

b) provar, atividade que consiste em trazer, de um lado, a prova deste saber dizer, executando corretamente os exercícios de avaliação com um comportamento conforme às exigências do sistema (sem esta prova, é o professor que pode questionar sua própria competência); do outro lado, a prova do interesse dado ao ensino (como resposta positiva à finalidade de captação do professor, sem a qual o professor perde um pouco da sua identidade). 
Os "papéis" de cada parceiro:

Do professor:

a) correspondente à finalidade de ensino, papel de apresentação dos documentos, das ferramentas, dos temas de trabalho, papel de descrição (resumos) e papel de explicação;

b) correspondente à finalidade de avaliação, papel de questionamento, papel de formulação das instruções de trabalho e papel de correção (por notas e apreciações);

c) correspondente à finalidade de captação, papéis de justificação e de valorização do objeto de saber e do programa, para fornecer aos alunos uma razão para aprender e então captar, a priori, seu interesse; papéis de sedução ou de ameaça expressos pelos diversos atos de linguagem (palavras de autoridade, de ironia, interpelações, promessas, desafios, provocações, felicitações etc.) que contribuem para gerir as trocas que acontecem durante a sessão de aula; enfim, papel de explicitações, expresso com a ajuda de relatos, anedotas, tiradas humorísticas e diversas estratégias de dramatização do discurso.

Do aluno:

a) correspondente à finalidade de aprender, papel de escuta (tratase de produzir signos de escuta) e papel de repetição (trata-se de repetir modelos de palavra);

b) correspondente à finalidade de provar, papéis de respondente (responder às perguntas e solicitações), de repetição (pela qual o aluno prova que entendeu e adquiriu um saber dizer), de perguntante (perguntas relativas ao objeto de saber que mostram o interesse a seu respeito).

\section{Comentários sobre o contrato}

O contrato é um quadro de reconhecimento no qual se subscrevem os parceiros para que se estabeleçam a troca e a intercompreensão. É, portanto, da ordem do imaginário social (o que não quer dizer que seja fictício). Mais uma vez, resulta da combinação das práticas e das representações sociais que constituem uma espécie de maior denominador comum. No entanto, este quadro de reconhecimento pode ser atualizado diferentemente segundo os parceiros que nele estão implicados, também pode modificar-se com o tempo, paralelamente à modificação das práticas e das representações sociais.

Queríamos apontar aqui algumas destas diferenciações. 
- Se estudarmos as instruções oficiais e os programas (que constituem o reflexo do ponto de vista que a instituição possui sobre o ensino), constataremos que não há sinais (ou são muito discretos) da finalidade de captação. Todavia, é por esta finalidade e pelos papéis que a ela estão ligados que o professor analisa os obstáculos à aquisição do saber e as dificuldades da avaliação. Isto ocorre tanto porque ele está numa situação ambígua frente à instituição que não considera esta finalidade (visto que é pressuposta), quanto porque ele avalia também a adequação ou a inadequação entre um sistema de ensino e a situação na qual se encontram os parceiros, os quais mudam na medida em que muda a sociedade.

Correlativamente, a finalidade que consiste em o aprendiz provar que tem interesse pelo ensino também não é considerada pela instituição. Isto pertence a uma representação idealizada a respeito do contrato de ensino, a qual atribuiria ao aluno a dupla qualificação de "desejo de saber"e de "aptidão para aprender". Portanto, não pode haver obstáculo à aprendizagem e, em consequência, nem ao ensino, e não há mais necessidade de provar nada. Ao aluno resta, então, colocar sua confiança na lei (o sistema escolar) e no seu guia (o professor).

Podemos considerar que essa idealização foi totalmente assumida até o final dos anos 1950. De fato, enquanto a seleção para o ingresso no $6 .^{\circ}$ ano pôde assegurar uma homogeneidade no imaginário social dos alunos: "aprender é bom e o sistema escolar é bom por definição", as finalidades de captação e de prova puderam ser consideradas pela sociedade como lógicas. A dúvida se instalou na instituição escolar assim que esta se abriu para a grande massa dos alunos, introduzindo um fator de diversificação social, até então desconhecido, que fez estourar esta evidência e até a colocou em questão.

Sob esse aspecto ainda, professores e alunos sempre foram percebidos e definidos, cada um à sua maneira, como uma entidade homogênea. $\mathrm{O}$ professor é considerado como aquele que tem certa competência (que seria a mesma para todos os professores) garantida por uma formação única relacionada ao saber (os concursos), o restante corresponde ao talento e à experiência. Quanto ao aluno, ele é percebido como quem faz parte de um grupo movido por um mesmo desejo de saber, tendo as mesmas referências sociais e as mesmas aptidões para aprender. Apenas recentemente se ouvem discursos, provenientes da instituição, que reconhecem deficiências no sistema devidas à não adequação da formação dos mestres e à não homogeneidade dos alunos em seus desejos, suas necessidades e suas aptidões (daí o sistema de setores e de salas de adaptação). ${ }^{2}$ 
- Encontramos outra idealização do contrato de ensino/aprendizagem na concepção do saber e da avaliação.

Em se tratando do ensino de francês, o saber é concebido como um conjunto homogêneo em torno da língua (gramática, vocabulário e ortografia) e da literatura (conhecimento das grandes obras conforme os grandes períodos históricos). Isto constitui o que podemos chamar de um saber "compacto" na medida em que ele se apresenta sob a forma de categorias imutáveis e de repertórios que o aluno deve conhecer. Ou seja, o que é proposto na aprendizagem é o conhecimento de um objeto abstrato categorizado (a língua ou a literatura) e não a manipulação-apropriaçãoprodução de usos múltiplos da linguagem para os fins de significação, de expressão, de comunicação e de criação. É por conta da diferença entre essa concepção idealizada do saber e a fraqueza das aquisições em matéria de expressão oral e escrita (sobretudo escrita) que pode ser explicado, em parte, o questionamento dos professores em relação ao que, dentre o que eles ensinam e que eles têm a responsabilidade de avaliar, o que de fato, tem fundamento e eficácia.

\section{Do contrato da SALA DE AULA AOS CONTRATOS DOS TEXTOS}

Na situação de sala de aula, desenvolvem-se diversas estratégias de palavra em relação com o quadro contratual acima definido.

Vimos que uma das características desse quadro diz respeito à finalidade de ensinar como atividade de transmissão de um saber do qual dissemos se tratar na realidade de um saber dizer, e é este saber que está sujeito a uma avaliação e não outro.

Duas estratégias são, então, possíveis no que diz respeito a este saber dizer:

a) uma delas consiste em defini-lo e materializá-lo de forma linguageira por meio das formas de exercícios particulares: ditados, análises gramaticais, comentários de texto, redações e dissertações. Neste caso, o objeto saber dizer pertence exclusivamente à instituição escolar (foi concebido por ela, nasceu nela), na medida em que não o encontramos em nenhuma outra situação de produção linguageira (apenas na escola, em sala de aula ou nas aulas de francês e em algumas outras disciplinas, são feitas redações ou dissertações).

Simultaneamente, os parceiros deste ato de troca são aqueles - e somente aqueles, institucionais - do contrato de ensino/aprendizagem: 
o professor e o aluno (para o aluno, o único destinatário-avaliador de seu trabalho é o professor).

b) a outra estratégia consiste em definir e materializar o saber dizer por meio das formas de expressão linguageira que supostamente existem nas trocas sociais fora da escola. Trata-se, então, de produzir textos num quadro contratual que, não sendo da escola, torna-se simulado no interior das atividades da sala de aula. Fala-se, segundo a moda: "ensino funcional do francês", "ensino comunicativo", "pedagogia dos textos autênticos", "estudos de caso".

Ao mesmo tempo, os parceiros deste ato de troca se desdobram. Pois, mesmo permanecendo identificados como professores/alunos (é a finalidade avaliar que os identifica assim no contrato), eles podem imaginar que exercem os papéis dos parceiros que estão implicados no contrato de produção-compreensão destes textos. Assim, redigindo, por exemplo, uma "crônica" ou uma "notícia", o aluno pode representar - de forma imaginária - o papel de um jornalista que escreve seu "jornal", e fazer seu destinatário representar o papel de leitor de um jornal. Isso acontece como se, além do olhar e da sanção escolares, ocorresse o olhar, e até a sanção social, de uma prática profissional particular.

Nesse caso, o objetivo de uma aula de francês não seria ensinar a Língua francesa (com um L maiúsculo), mas sim ensinar como se constroem os objetivos de significação num ato de comunicação (que seria literário), por meio das formas da matéria linguageira.

Em tal perspectiva, os problemas do ensino desta disciplina não se apresentam em termos de oposições: língua ou comunicação, exemplos fora do contexto ou textos autênticos, ortografia e conjugação ou exercícios de expressão. Encontram sua solução procedendo da seguinte maneira:

1) recusar qualquer atividade de ensino que se contenta em aplicar exercícios puramente formais, pois estes não consideram os objetivos de sentido contidos nos atos de linguagem. No entanto, a ortografia, o emprego de tal artigo, de tal tempo verbal, de tal preposição ou de tal pronome é sempre revelador de um objetivo de sentido;

2) visto que não há ato de linguagem sem objetivo de sentido, construir atividades pedagógicas (existem várias possíveis) que permitem pôr em relação a descoberta e a manipulação das formas da linguagem com os contratos e as estratégias de fala dos parceiros duma troca (tratando-se de 
textos orais ou escritos), para mostrar que o emprego das formas serve para construir as identidades e intenções sociais e individuais dos sujeitos falantes.

Assim, não haveria mais nenhum exercício de localização das formas, nenhum exercício de manipulação da língua, nenhum exercício de criação que não fosse motivado pela descoberta simultânea de um objetivo de identidade. É o melhor meio de fazer entender que as palavras têm poder. As palavras não matam, claro, mas têm o poder, segundo sua situação de emprego, tanto de ferir até a morte como de fazer renascer a vida. ${ }^{3}$

Parece-me que a escola possui tanto a vocação de conscientizar sobre esses objetivos da comunicação social quanto a de ensinar os sistemas da língua. Mais exatamente, ela tem a vocação de ensinar os sistemas de uma língua (ensinada como língua materna, segunda ou estrangeira) por meio dos objetivos da comunicação, isto é, da construção da identidade do sujeitoaluno: fazer perceber os contratos, as normas, os rituais, para melhor dominar as estratégias. Assim, o ensino da língua se torna o ensino da construção do sentido por meio da língua.

\section{THE COMMUNICATION CONTRACT IN THE CLASSROOM}

ABSTRACT: The act of communication cannot be reduced to a symmetrical relationship between a transmitter and a receiver. The conditions under which the speaking subjects recognize this reciprocal right to speak and construct meaning for the act of communication to take place must be analyzed. This act occurs in a language exchange in which the partners recognize each other's right to speak, that is, both enter a contract in which they seek common principles, relevance, influence and regulation. In a classroom situation, the partners use their interaction in a way that co-constructs their identities, objectives and roles so that the senses can be the result of the act of communication.

KEYWORDS: Communication contract. Teacher. Teaching. Classroom.

\section{NOTAS}

1. Encontraremos uma definição mais detalhada desta noção em Charaudeau (1991).

2. Ver também o ponto de vista sociológico sobre esta questão de Bourdieu e Champagne (1992).

3. É neste espírito que foi escrita nossa Grammaire du sens et de l'expression. Paris: Hachette, 1992. 


\section{REFERÊNCIAS}

BOURDIEU, P.; CHAMPAGNE, P. Les exclus de l'intérieur. Revista Actes de la recherche en sciences sociales, n. 91/92, mar. 1992, Maison des sciences de l'homme. Paris: Éditions de Minuit.

CHARAUDEAU, P. Contrats de communication et ritualisations des débats télévisés. In: La Télévision, les débats culturels, "Apostrophes". Paris: Didier Erudition, 1991. (Coll. Langages, Discours et Sociétés).

CHARAUDEAU, P. Grammaire du sens et de l'expression. Paris: Hachette, 1992.

PARRET, H. La communication et les fondements de la pragmatique. Revista Verbum, t. XII, Presses Universitaires de Nancy, 1989.

GOFFMAN, E. Les rites d'interaction. Paris: Éditions de Minuit, 1974.

Patrick Charaudeau é professor emérito da Universidade de Paris 13. Um dos fundadores do Centro de Análise do Discurso, é pesquisador do CNRS (Laboratório de Ciências Políticas). Há mais de 30 anos, investiga os usos da linguagem, a relação entre discurso, sentido e identidade, em diversos campos como a mídia (imprensa, televisão, publicidade), a política e a literatura. Tem vários artigos e livros publicados em português.

Site: patrick-charaudeau.com 